\title{
Radiological Changes observed in Covid 19 Pneumonia and utilization of CT scan as a screening tool along with a real-time reverse transcriptase-polymerase chain reaction (rRT-PCR) for effective diagnosis
}

\author{
Bisma Mukhtar ${ }^{1}$, Muhammad Omar Mukhtar ${ }^{2}$, Bilal Malik $^{3}$
}

\section{Abstract}

Objective: In this review article, Symptom and diagnosis of SARS-COV-2 or more commonly known as COVID-19 viral infection have been reviewed based on current literature. The CT scan, rRT-PCR results for infected patients have been focused on.

Keywords: COVID-19, SARS-COV-2, Pneumonia, Radiological Changes, CT, rRT-PCR, Screening Tool

\section{Introduction}

Coronaviruses (enveloped RNA viruses) are a group of viruses giving rise to illnesses such as the common cold, Severe acute respiratory syndrome (SARS), and the Middle East respiratory syndrome (MERS) $(1,2,3)$.

Coronavirus disease of 2019 (Covid 19) is an infectious disease caused by a new coronavirus; severe acute respiratory syndrome coronavirus 2 (SARS COV 2) which emerged in Wuhan, China spreading globally resulting in the coronavirus pandemic of 2019-2020, as declared by WH Recent evidence shows that this SARS COV 2 shares similar pathogenesis of pneumonia to that caused by SARS-COV and MERS-COV.O in March 2020 (4,5).

Recent evidence shows that this SARS COV 2 shares similar pathogenesis of pneumonia to that caused by SARS-COV and MERS-COV $(3,6)$.

It is a zoonotic disease belonging to the beta coronaviruses and indicating the bat as the natural host as identified by several research groups (7).

\section{Before 2019}

There are seven types of Coronaviruses (CoV) known to infect humans: 229E (alpha CoV), NL63 (alpha CoV), OC43 (beta CoV), HKU1 (beta CoV), MERS-CoV (beta $\mathrm{CoV}$ ), SARS-CoV (beta CoV), and the most recent SARS$\mathrm{CoV}-2$. Most of these cause self-limiting upper respiratory infection or the 'common cold'; however, occasionally other organ systems are involved and may cause severe complications (8). The earliest viral isolate of $\mathrm{CoV}$ was done in 1960 (9).
Earlier published studies on MERS-CoV indicate most common finding on chest radiograph to be ground-glass opacities $(66 \%)$ followed by lung consolidation (18\%)(10) with a preference towards lower lobes and the peripheral zones (11). Another study on MERS-CoV suggested that using a similar scoring criterion to Covid 19, patients with a score of $>10$ on day 10 of viral exposure required intubation to minimize fatal outcomes (12).

\section{Signs and Symptoms of COVID-19}

Covid 19 usually manifests as systemic as well as/or respiratory symptoms which consist of fever, shortness of breath, dry cough, myalgia, headache, fatigue, and breathing difficulty (13).

Rare symptoms include nausea, vomiting, diarrhea, nasal congestion, chest tightness, and palpitations (14). In severe disease manifestation, it may cause pneumonia, kidney failure, severe acute respiratory syndrome, and death (2).

Remarkable signs of viral pneumonia comprise of decreased oxygen saturation, blood gas deviations, lymphopenia, increased PT (Prothrombin Time), elevated levels of LDH (Lactate Dehydrogenase) and inflammatory markers (C-reactive protein, D-dimers, and proinflammatory cytokines) (15).

Novel reports also suggest that gastrointestinal and asymptomatic infections are also seen in young children $(4,16)$. 
The most prominent risk factors for mortality are old age (>70 years) and underlying health issues; hypertension being the most frequent, proceeded by diabetes mellitus and coronary artery disease $(17,18)$.

\section{Diagnosis}

Covid 19 is a highly contagious disease leading to a large increase in the number of affected individuals day by day thereby rendering diagnostic tools a crucial part to overcome the crisis. In relation to rRT-PCR, chest CT imaging seems to be a more practical, dependable and fast method to assess and diagnose COVID-19, especially in areas of epidemic spread (19).

As chest CT is routinely used for the diagnosis of pneumonia hence forming a convenient tool for diagnostic workup, disease progression, prognosis and follow up of the disease (20).

Imaging has limited sensitivity in the early course of the disease but in severe disease, only $3 \%$ are found to have normal chest $\mathrm{x}$ rays thus making it an effective tool for diagnosis $(21,22)$.

\section{RT-PCR}

The definitive diagnostic test for Covid 19 is Real-Time Reverse Transcriptase-Polymerase Chain Reaction (RTPCR) so far and is considered to have low sensitivity, reported being ranging between $60-70 \%$ but relatively high specificity (23) depending on the country, thereby rendering false negatives a huge problem to label a person disease-free.

However, the long processing time and uncertain outcomes of RT-PCR in the early course of the disease have made it evident the need for an effective screening tool to complement the early diagnosis of the disease.

\section{X-RAY Changes}

Findings observed in chest $\mathrm{x}$-ray include asymmetric migratory lesions, bilateral perihilar infiltration, and illdefined patchy or diffuse air space opacities (consolidation) which progressed diffusely later eventually indicating deterioration. Mild bronchiectasis was also observed in the lesion. However, diagnosing Covid 19 on chest radiography is likely to be challenging specifically in patients with mild symptoms and low severity $(24,25)$.

The figures mentioned above shows the course of progression of changes observed in Covid 19 pneumonia starting from ill-defined opacities in the lower lobes as shown in (figure 1) followed by radiological worsening with bilateral and peripheral alveolar consolidations (figure 2) leading to radiological worsening demonstrating ARDS (figure 3) ultimately showing extensive ground glass opacities (figure 4).

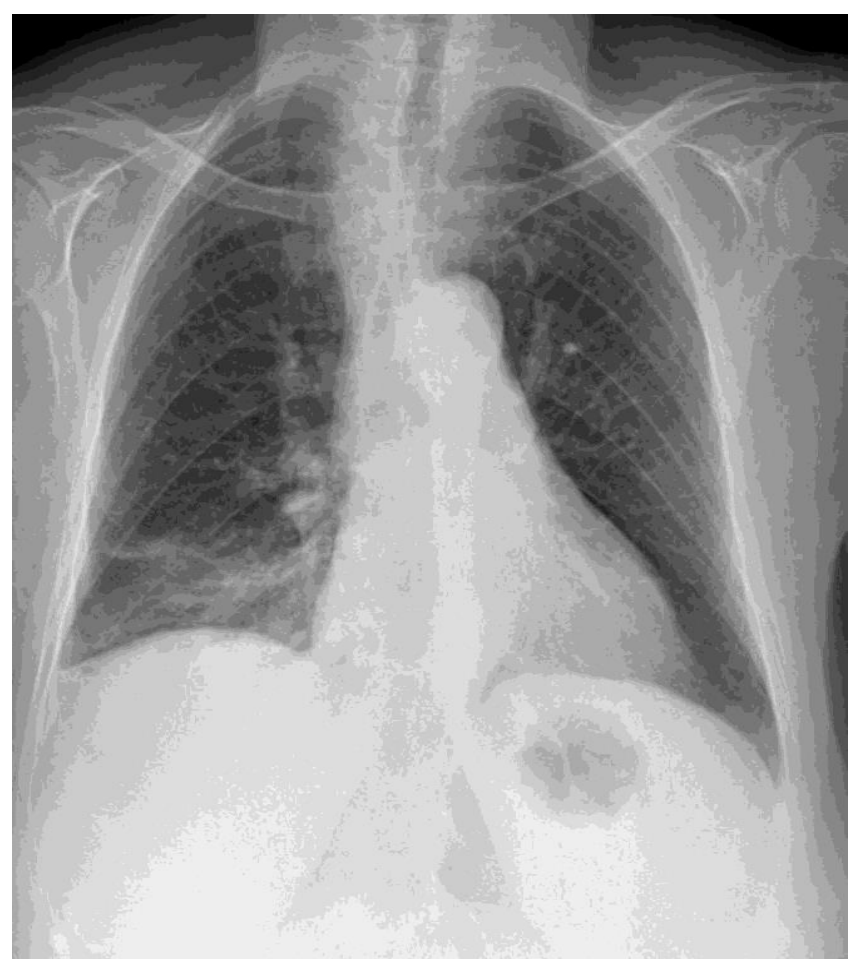

Figure 1: Opacity in the right lower lobe (Stage 1) (26).

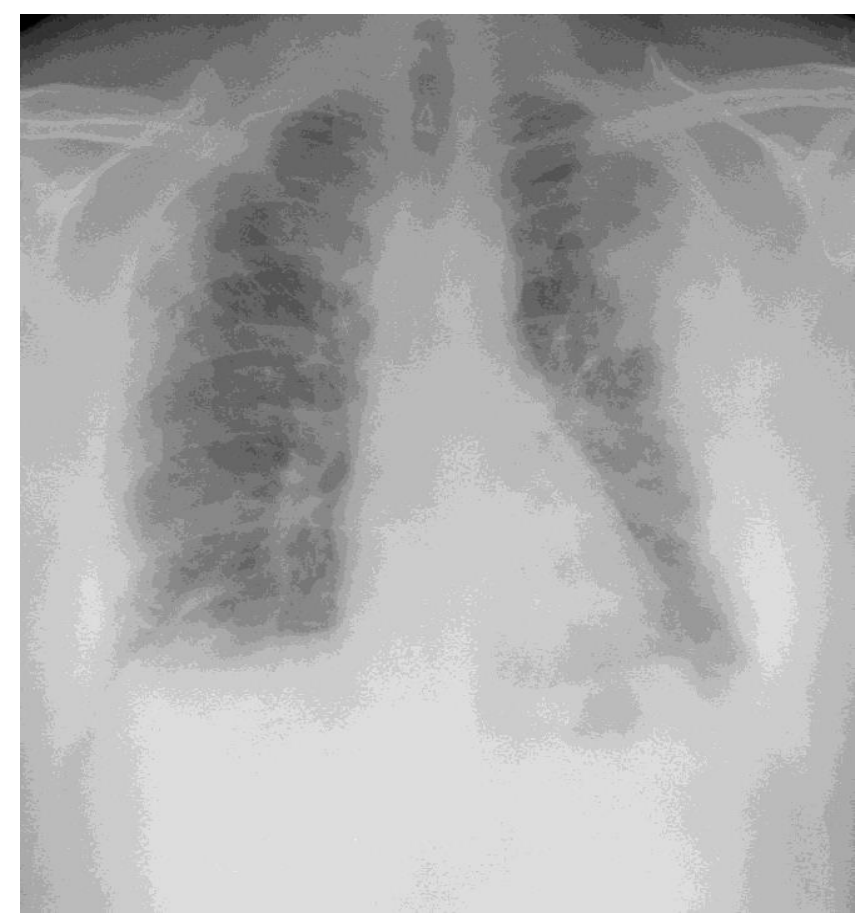

Figure 2: Radiological worsening with bilateral and peripheral alveolar consolidations, more prominent in the left lung (Stage 2) (27). 


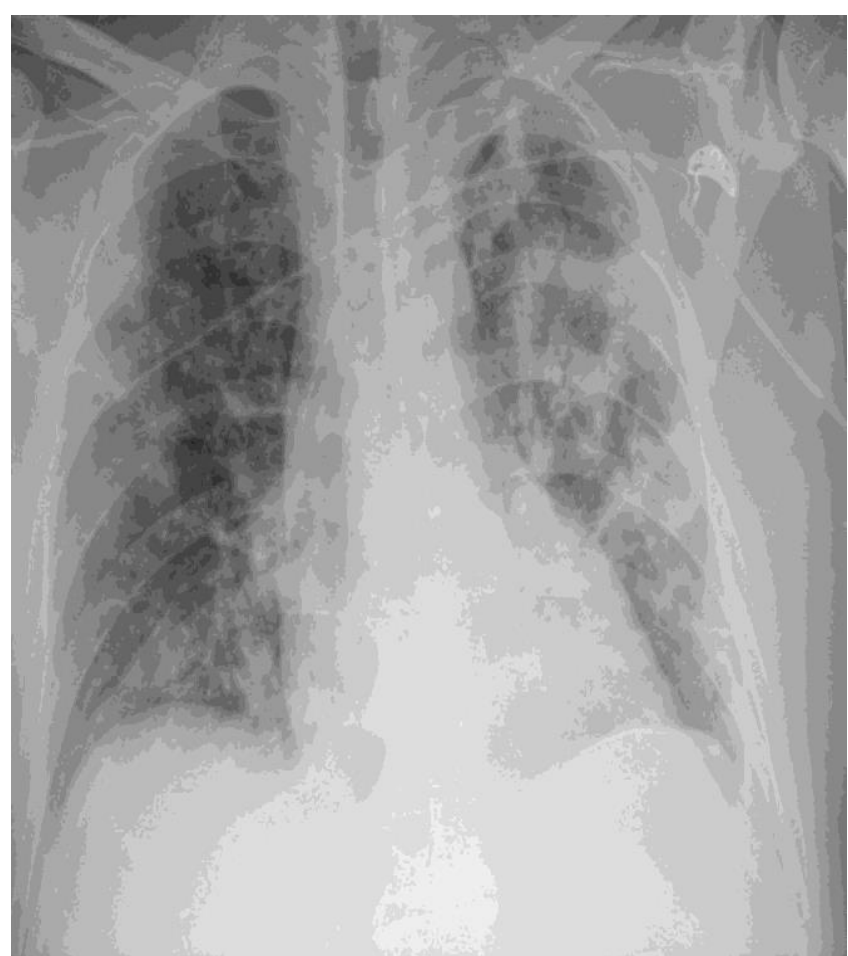

Figure 3: Radiological worsening with disease progression and findings consistent with ARDS (Stage 3) (27).

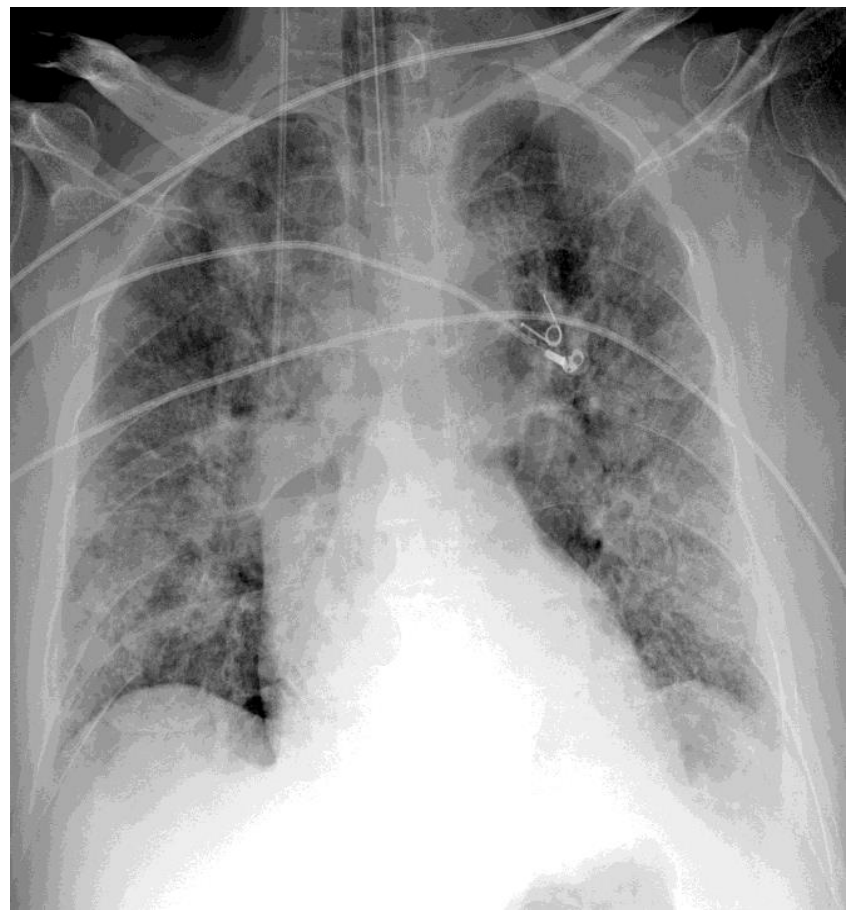

Figure 4: AP chest radiograph showing extensive bilateral ground-glass opacities (Stage 3) (28).

\section{Computer Tomography (CT) CHANGES}

CT scan has appeared to be a sensitive modality in the detection of Covid 19 pneumonia even in initial stages of disease (asymptomatic population) and may be used as a screening tool along with RT-PCR in patients having recent travel history or contact with a Covid positive individuals (25).

The average lead time appeared to be 3 days in the diagnosis of viral infection by CT scan concerning RTPCR (29).

Imaging by chest radiography typically demonstrates diffuse or patchy asymmetric airspace opacities, identical to other pneumonia types of coronavirus origin (20).

Single inspiratory films of CT were taken in a study carried out in China establishing that CT scans showed groundglass opacities (GGO) in $56 \%$ patients while $18 \%$ had no significant radiological findings initially. Peripheral, subpleural, and bilateral circumscribed round nodular GGO are the classic CT findings, nevertheless, they are indefinite. Alveolar exudates, consolidation, crazy paving appearance (GGO with interlobular septal thickening), reverse halo sign, and linear opacities all are included in radiological findings as the disease progresses. Early in the disease process, the lesions are unilateral, later manifesting bilaterally. In $88 \%$ of the cases, lower lobes are predominantly involved (4).

In another study for 18 out of 21 patients, the total CT score peaked after 10 days of the onset of symptoms with a calculated total score of 6 and then gradually decreased first forming residual parenchymal bands followed by the absorption stage (26 days after symptom onset) in which consolidation and paving pattern started absorbing gradually (4).

A semi-quantitative system of scoring was employed to evaluate the pulmonary involvement, the total chest CT score was calculated as the total lung involvement (5 pulmonary lobes, score 1-5 for each lobe, with a range from 0 as none and 25 as maximum). 0 , no involvement; $1,<5 \%$ involvement; 2, 25\% involvement; $3, \quad 26 \%-49 \%$ involvement; 4, 50\%-75\% involvement and 5, >75\% involvement (30).

Four stages were defined, depending upon lung involvement on CT scans:

Stage 1/Early Stage (0-4 days): GGO in $75 \%$ of patients, Total CT score $2 \pm 2$

Stage 2/Progressive Stage (5-8 days): expanded crazy paving pattern in $53 \%$ of patients, Total CT score $6 \pm 4$

Stage 3/ Peak Stage (9-13 days): consolidation in 91\% patients, Total CT score peaked at $7 \pm 4$

Stage 4/ Absorption Stage (>=14 days): the gradual resolution of consolidation in $75 \%$ of patients, Total CT score $6 \pm 4$ (30).

Centrilobular nodules, pneumothorax, mediastinal lymphadenopathy, pleural effusions, and tree in bud opacities may indicate atypical causes of pneumonia.

Involvement of more than four lung zones bilaterally and gradual deterioration of airspace consolidation on CT chest greater than 12 days after the onset of symptoms despite aggressive treatment is paired with worse outcomes (20). 


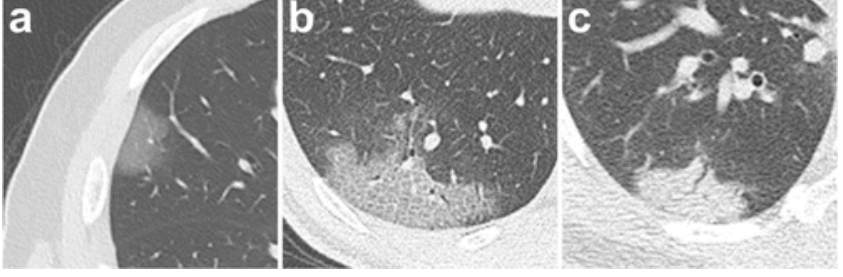

Figure 5: CT chest findings of pneumonia by COVID-19 as seen on trans axial images. (a) Early-stage showing GGO as the typical radiological feature distributed subpleural in the lower lobes (Total CT score 2 \pm 2 ) (31). (b) Progressive stage demonstrating crazy-paving pattern (Total CT score $6 \pm 4$ ) (c) Peak stage showing Consolidation (Total CT score 7 \pm 4 ) (30).

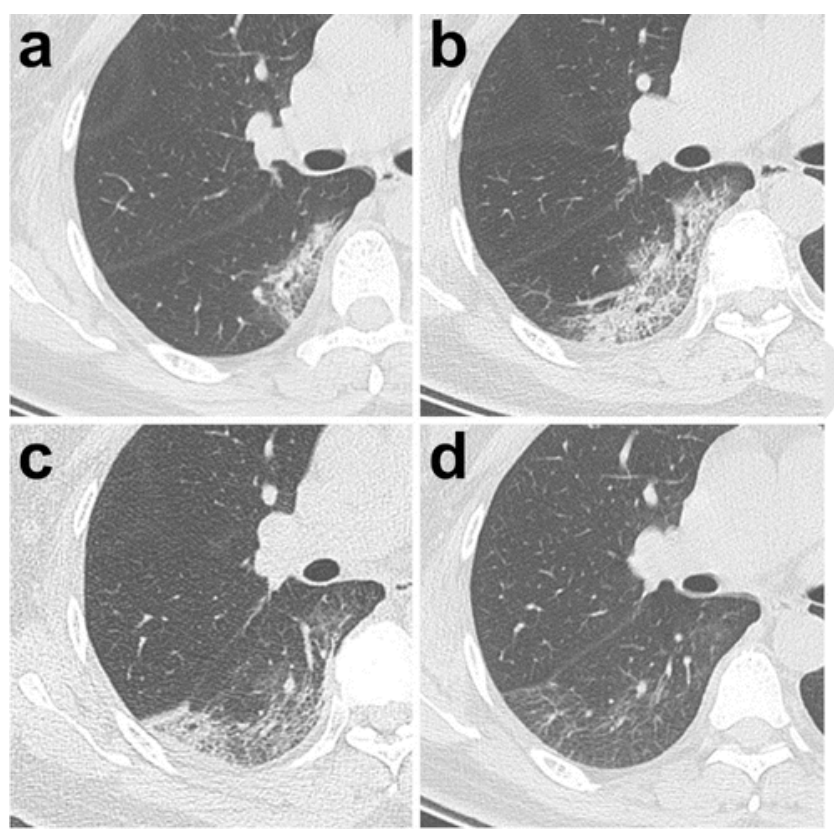

Figure 6: CT chest findings of a 47-year-old Covid 19 case who presented with a constant fever of $38.8^{\circ} \mathrm{C}$ for 3 consecutive days. (a) EARLY STAGE (day 3), subpleural GGO in addition to partial consolidation as shown in the lower right lobe (b) PROGRESSIVE STAGE (day 7), expanded zone of GGO with overlapping inter-and intralobular thickening of septa (the crazy-paving pattern) and partial consolidation. (c) PEAK STAGE (day 11), GGO with subpleural consolidation. (d) ABSORPTION STAGE (day 20), continued resolution with nominal remaining GGO and parenchymal bands (30).

\section{Comparison of covid 19 with non-covid19 pneumonia}

Despite the fact that the imaging features are closely related to those of SARS and MERS, the bilateral involvement of the lungs on initial imaging is more likely to be associated with COVID-19 on the other hand, the early abnormalities were seen in SARS and MERS frequently demonstrate a unilateral spread (20).

Compared to Covid 19, Non-Covid 19 pneumonia is presumably to have peripheral and central distribution, pleural thickening, air bronchogram, pleural effusion and lymphadenopathy that are not characteristically seen in pneumonia caused by Covid 19 (32).

In $83 \%$ of the patients with MERS, the initial radiographic changes include multifocal airspace opacities later extending into perihilar and upper lobes with 33\% leading to lung fibrosis in patients having prolonged ICU admission along with extensive lung involvement in the acute phase of the disease.

In patients having SARS, fibrosis may also occur in about $1 / 3$ rd of the patients in addition to traction bronchiectasis and rarely honeycombing (19).

However, in other types of viral pneumonia, the classical pattern is observed as bilateral consolidations, bronchial wall thickening, nodular opacities, and mild pleural effusions. Lobar consolidation is an uncommon finding in viral pneumonias (33).

\section{Sensitivity of ct scan in relation to RT-PCR}

Typical chest CT findings seem to play a pivotal role in screening and diagnosing individuals having negative results from swab test thus having higher sensitivity comparable to RT PCR, however, unremarkable chest imaging does not rule out the infection as initial findings may be normal in about $14 \%$ of the patients $(34,35)$.

Another study presented by a team at the Taizhou Enze Medical Center (Group) Enze Hospital on 19 February 2020 revealed that a chest CT scan for COVID-19 has greater sensitivity $(98 \%)$ in comparison to the polymerase chain reaction $(71 \%)(36)$.

Owing to the delays in laboratory testing, limited resources and a huge number of symptomatic individuals CT might serve as an effective screening tool in diagnosing individuals having false negative RT-PCR to control the pandemic (25)

\section{Conclusion}

In conclusion, the emergence of this pandemic poses many challenges for our health care systems and much research on effective strategies needs to be developed with a multidisciplinary approach to combat this crisis.

Initial changes evident on CT scan include bilateral groundglass opacities, consolidation, septal thickening, and paving opacities peaking on the 10th day after symptom onset and resolving gradually after 26th day. An integrated criterion combining CT as well as rRT PCR is desirable and will help to accomplish greater reliability of diagnosis in clinical practice. Chest $\mathrm{CT}$ in addition to being fast, reliable and relatively easy to perform has high specificity but moderate sensitivity in differentiating between Covid 19 and non-Covid 19 pneumonia hence exceeding DNA detection tests like RT-PCR (2).

Radiologists are encouraged to use the scoring system mentioned earlier and make a confirmatory diagnosis to lessen the burden of rRT PCR and decrease the overall anxious atmosphere in ER. History of contact and travel history plays a fundamental role in diagnosing and preventing the spread. Thus, relying on the exposure 
history, clinical symptoms and CT features rather than rRTPCR tests alone would aid more rapid detection of disease and may allow for efficient control of viral transmission. Quarantining the patient is also critical for controlling the transmission due to the highly contagious nature of this disease.

\section{Acknowledgement, Funding: None.}

Author's contributions: BM, MOM, BM; Study design, Data Collection, review the literature, BM; Manuscript preparation and Revisions

Conflict of interest: The authors declare that they have no conflict of interest.

\section{References}

1. Corman VM, Muth D, Niemeyer D, Drosten C. Chapter Eight Hosts and Sources of Endemic Human Coronaviruses. In: Kielian M, Mettenleiter TC, Roossinck MJ, editors. Advances in Virus Research. 100: Academic Press; 2018. p. 163-88.

2. Yin Y, Wunderink RG. MERS, SARS and other coronaviruses as causes of pneumonia. Respirology. 2018;23(2):130-7.

3. Li Y-C, Bai W-Z, Hashikawa T. The neuroinvasive potential of SARS-CoV2 may play a role in the respiratory failure of COVID-19 patients. Journal of Medical Virology.n/a(n/a).

4. Velavan T, Meyer C. The Covid-19 epidemic. Tropical Medicine \& International Health. 2020;25.

5. The Lancet Infectious D. COVID-19, a pandemic or not? The Lancet Infectious Diseases.

6. Wang L-s, Wang Y-r, Ye D-w, Liu Q-q. A review of the 2019 Novel Coronavirus (COVID-19) based on current evidence. International Journal of Antimicrobial Agents. 2020;55:105948.

7. Guo Y-R, Cao Q-D, Hong Z-S, Tan Y-Y, Chen S-D, Jin H-J, et al. The origin, transmission and clinical therapies on coronavirus disease 2019 (COVID-19) outbreak - an update on the status. Military Medical Research. 2020;7(1):11.

8. Corman VM, Muth D, Niemeyer D, Drosten C. Hosts and sources of endemic human coronaviruses. Advances in virus research. 100: Elsevier; 2018. p. 163-88.

9. Kendall E, Bynoe M, Tyrrell D. Virus isolations from common colds occurring in a residential school. British medical journal. 1962;2(5297):82.

10. Das KM, Lee EY, Jawder SEA, Enani MA, Singh R, Skakni L, et al. Acute Middle East Respiratory Syndrome Coronavirus: Temporal Lung Changes Observed on the Chest Radiographs of 55 Patients. American Journal of Roentgenology. 2015;205(3):W267-S74

11. Das KM, Lee EY, Enani MA, AlJawder SE, Singh R, Bashir S, et al. CT Correlation With Outcomes in 15 Patients With Acute Middle East Respiratory Syndrome Coronavirus. American Journal of Roentgenology. 2015;204(4):736-42.

12. Cha MJ, Chung MJ, Kim K, Lee KS, Kim TJ, Kim TS. Clinical implication of radiographic scores in acute Middle East respiratory syndrome coronavirus pneumonia: Report from a single tertiaryreferral center of South Korea. European Journal of Radiology. 2018;107:196-202.

13. Shi F, Yu Q, Huang W, Tan C. 2019 Novel Coronavirus (COVID19) Pneumonia with Hemoptysis as the Initial Symptom: $C T$ and Clinical Features. Korean J Radiol. 2020;21(5):537-40.
14. Lai C-C, Shih T-P, Ko W-C, Tang H-J, Hsueh P-R. Severe acute respiratory syndrome coronavirus 2 (SARS-CoV-2) and coronavirus disease-2019 (COVID-19): The epidemic and the challenges. International Journal of Antimicrobial Agents. 2020;55(3):105924.

15. Lim J, Jeon S, Shin H-Y, Kim MJ, Seong YM, Lee WJ, et al. Case of the Index Patient Who Caused Tertiary Transmission of Coronavirus Disease 2019 in Korea: the Application of Lopinavir/Ritonavir for the Treatment of COVID-19 Pneumonia Monitored by Quantitative RT-PCR. J Korean Med Sci. 2020;35(6).

16. Zhu Y, Liu Y-L, Li Z-P, Kuang J-Y, Li X-M, Yang Y-Y, et al. Clinical and CT imaging features of 2019 novel coronavirus disease (COVID-19). Journal of Infection.

17. Palacios Cruz M, Santos E, Velázquez Cervantes MA, León Juárez M. COVID-19, una emergencia de salud pública mundial. Revista Clínica Española. 2020.

18. Zhou F, Yu T, Du R, Fan G, Liu Y, Liu Z, et al. Clinical course and risk factors for mortality of adult inpatients with COVID-19 in Wuhan, China: a retrospective cohort study. The Lancet. 2020.

19. Ai T, Yang Z, Hou H, Zhan C, Chen C, Lv W, et al. Correlation of Chest CT and RT-PCR Testing in Coronavirus Disease 2019 (COVID-19) in China: A Report of 1014 Cases. Radiology.0(0):200642.

20. Hosseiny M, Kooraki S, Gholamrezanezhad A, Reddy S, Myers L. Radiology Perspective of Coronavirus Disease 2019 (COVID-19) Lessons From Severe Acute Respiratory Syndrome and Middle East Respiratory Syndrome. American Journal of Roentgenology. 2020:15 .

21. Guan W-j, Ni Z-y, Hu Y, Liang W-h, Ou C-q, He J-x, et al. Clinical Characteristics of Coronavirus Disease 2019 in China. New England Journal of Medicine. 2020.

22. Rodrigues JCL, Hare SS, Edey A, Devaraj A, Jacob J, Johnstone A, et al. An update on COVID-19 for the radiologist - A British society of Thoracic Imaging statement. Clinical Radiology.

23. Kanne JP, Little BP, Chung JH, Elicker BM, Ketai LH. Essentials for Radiologists on COVID-19: An Update-Radiology Scientific Expert Panel. Radiology.0(0):200527.

24. Cheng S-C, Chang Y-C, Fan Chiang Y-L, Chien Y-C, Cheng M, Yang C-H, et al. First case of Coronavirus Disease 2019 (COVID19) pneumonia in Taiwan. Journal of the Formosan Medical Association. 2020;119(3):747-51.

25. Lee EYP, Ng M-Y, Khong P-L. COVID-19 pneumonia: what has CT taught us? The Lancet Infectious Diseases.

26. Lorente E. COVID-19 Pneumonia Case, rID : 75189. Radiopaedia; 2020 .

27. Lorente E. Rapidly progressive ARDS secondary to COVID-19 infection, Case 16660. Eurorad; 2020

28. Macori F. COVID-19 Pneumonia Case, rID : 74867. Radiopaedia.

29. Li Y, Xia L. Coronavirus Disease 2019 (COVID-19): Role of Chest $\mathrm{CT}$ in Diagnosis and Management. American Journal of Roentgenology. 2020:1-7

30. Pan F, Ye T, Sun P, Gui S, Liang B, Li L, et al. Time Course of Lung Changes On Chest CT During Recovery From 2019 Novel Coronavirus (COVID-19) Pneumonia. Radiology. 2020:200370.

31. He F, Deng Y, Li W. Coronavirus disease 2019: What we know? J Med Virol. 2020;92(7):719-25.

32. Bai HX, Hsieh B, Xiong Z, Halsey K, Choi JW, Tran TML, et al Performance of radiologists in differentiating COVID-19 from viral pneumonia on chest CT. Radiology. 2020:200823. 
33. Franquet T. Imaging of Pulmonary Viral Pneumonia. Radiology. 2011;260(1):18-39.

34. Yang W, Cao Q, Qin L, Wang X, Cheng Z, Pan A, et al. Clinical characteristics and imaging manifestations of the 2019 novel coronavirus disease (COVID-19):A multi-center study in Wenzhou city, Zhejiang, China. Journal of Infection. 2020;80(4):388-93.
35. Li D, Wang D, Dong J, Wang N, Huang H, Xu H, et al. FalseNegative Results of Real-Time Reverse-Transcriptase Polymerase Chain Reaction for Severe Acute Respiratory Syndrome Coronavirus 2: Role of Deep-Learning-Based CT Diagnosis and Insights from Two Cases. Korean J Radiol. 2020;21(4):505-8.

36. Fang Y, Zhang H, Xie J, Lin M, Ying L, Pang P, et al. Sensitivity of Chest CT for COVID-19: Comparison to RT-PCR. Radiology. 2020:200432.

Copyright (C) 2020 The Author(s); This is an open-access article distributed under the terms of the Creative Commons Attribution License (http://creativecommons.org/licenses/by/4.0), (CC BY NC) which permits unrestricted use, distribution, and reproduction in any medium, provided the original work is properly cited. International journal of Medical Science and Discovery. 